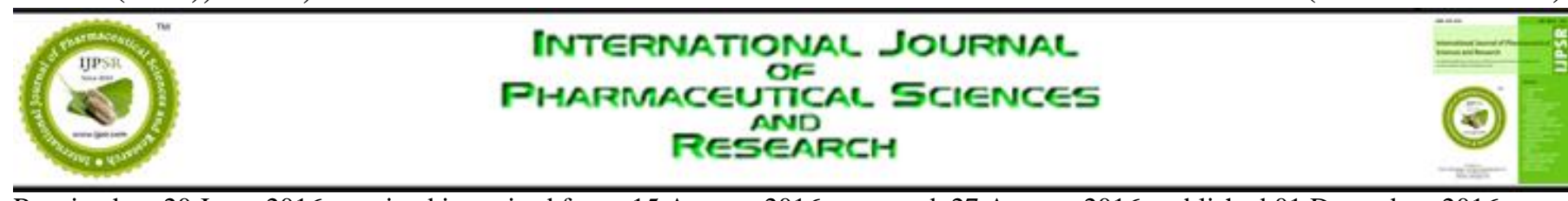

Received on 20 June, 2016; received in revised form, 15 August, 2016; accepted, 27 August, 2016; published 01 December, 2016

\title{
METHOD DEVELOPMENT AND VALIDATION FOR THE ESTIMATION OF IDELALISIB IN RABBIT PLASMA BY HPLC
}

\author{
A. Suneetha ${ }^{* 1}$ and D. Sharmila ${ }^{2}$
}

Department of Pharmaceutical Analysis ${ }^{1}$, Hindu College of Pharmacy, Amaravathi road, Guntur-522 002, Andhra Pradesh, India.

Department of Pharmaceutical Analysis ${ }^{2}$, V.V. Institute of Pharmaceutical Sciences, Gudlavalleru521356, Andhra Pradesh, India.

Keywords:

Idelalisib, Ibrutinib, Anticaner, Rabbit Plasma

\section{Correspondence to Author: \\ Dr. A. Suneetha}

Professor \& HOD,

Department of Pharmaceutical

Analysis, Hindu College of Pharmacy,

Amaravathi road, Guntur - 522 002,

Andhra Pradesh, India.

Email: drasuneetha@gmail.com
ABSTRACT: A simple, rapid, sensitive, and accurate high performance liquid chromatography was developed for determination of Idelalisib (IL) in rabbit plasma using Ibrutinib as internal standard (IS). Idelalisib is a phosphoinositide 3-kinase inhibitor indicated in the treatment of chronic lymphocytic leukemia (CLL), relapsed follicular B-cell non-Hodgkin lymphoma (FL), and relapsed small lymphocytic lymphoma (SLL). The analytes and IS were separated on a ODS $(250 \mathrm{~mm} \times 4.6 \mathrm{~mm}, 5 \mu \mathrm{m})$ column using Mobile phase composition as Buffer and Acetonitrile in the ratio of $85: 15 \mathrm{v} / \mathrm{v} \%$. The total chromatographic runtime is $10.0 \mathrm{~min}$ with retention time for IL and IS at 7.195 , and $5.435 \mathrm{~min}$, respectively with a flow rate $1 \mathrm{ml} / \mathrm{min}$. The method is validated over a dynamic linear range of $0.02-4 \mu \mathrm{g} / \mathrm{mL}$ for IL with a correlation coefficient of r2 0.999 . The method was validated as per the USFDA guidelines and the results were within the acceptance criteria for selectivity, sensitivity, linearity, precision, accuracy, recovery stability of solution and stability of solution in plasma.
INTRODUCTION: Idelalisib is an oral phosphatidylinositol 3-kinase delta (PI3K $\delta$ ) inhibitor ${ }^{1}$. It had clinically significant activity with an acceptable toxicity profile in patients with relapsed or refractory chronic lymphocytic leukemia, follicular B cell non-Hodgkin's lymphoma and small lymphocytic lymphoma ${ }^{2,3}$. Idelalisib has demonstrated activity in indolent BNHL (iB-NHL) and is approved for use as monotherapy in patients with follicular lymphoma and small lymphocytic lymphoma and in combination with rituximab in patients with chronic lymphocytic leukemia ${ }^{4}$.

\begin{tabular}{|l|c|}
\hline QUICK RESPONSE CODE & \begin{tabular}{c} 
DOI: \\
DOl link: http://dx.doi.org/10.13040/IJPSR.0975-8232.7 (12).4998-05 \\
\hline
\end{tabular} \\
\hline
\end{tabular}

Treatment of lymphoma cells with Idelalisib has been shown to result in inhibition of chemotaxis and adhesion, and reduced cell viability. Chemically Idelalisib is 5-fluoro-3-phenyl-2-[(S)-1(9H-purin-6-ylamino)-propyl] - $3 H$ - quinazolin- 4 one, with molecular formula $\mathrm{C}_{22} \mathrm{H}_{18} \mathrm{FN}_{7} \mathrm{O}^{5,6}$.

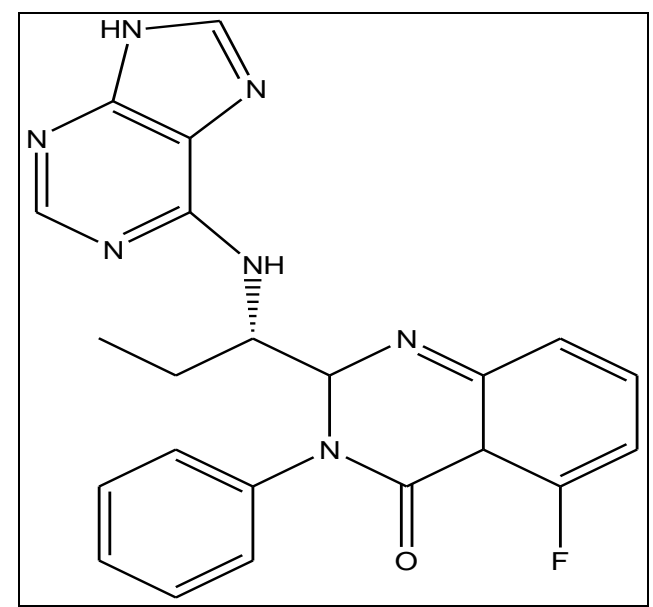

FIG.1: STRUCTURE OF IDELALISIB 
Ibrutinib is a bruton tyrosine kinase (BTK) inhibitor effective in patients with chronic lymphocytic leukemia ${ }^{7}$. Ibrutinib is an orally available small molecule that forms an irreversible covalent bond with the Cys481 of BTK kinase ${ }^{8}$. Ibrutinib is also indicated for the treatment of patients with Waldenström's Macroglobulinemia (WM). IUPAC Name 1-[(3R)-3-[4-amino-3-(4phenoxyphenyl)-1H-pyrazolo [3,4-d]pyrimidin-1yl]piperidin-1-yl]prop-2-en-1-one ${ }^{9}$.

\subsection{Reagents and chemicals:}

The pure samples of Idelalisib and Ibrutinib were obtained from Selleckchem.com LLC supplied by Pro lab marketing. HPLC grade Acetonitrile, HPLC grade Methanol and all other chemicals were obtained from Merck chemical division, Mumbai. HPLC grade water obtained from Milli-Q water purification system was used throughout the study.

\subsection{Instrumentation:}

Chromatography was performed with waters 2695 HPLC provided with high speed auto sampler, column oven, degasser and \& 2996 PDA detector to provide a compact and with class Empower-2 software.

\subsection{Chromatographic method:}

The separation was carried on ODS C18 analytical column $(250 \mathrm{~mm} \times 5 \mathrm{~mm} \times 4.6 \mu \mathrm{m})$ using mobile phase Buffer and Acetonitrile in the ratio of $85: 15 \% \mathrm{v} / \mathrm{v}$ and flow rate is $1 \mathrm{ml} / \mathrm{min}$. The Injection volume was $10 \mu \mathrm{l}$ and the run time was $10 \mathrm{~min}$. The temperatures of column and auto sampler were maintained at $30^{\circ} \mathrm{C}$ and $5^{\circ} \mathrm{C}$ respectively. The detection was carried at wavelength $270 \mathrm{~nm}$.

\subsection{Buffer Preparation:}

$1 \mathrm{ml}$ of $0.1 \%$ Perchloric acid was transferred into $1000 \mathrm{~mL}$ volumetric flask and made the volume to produce $1000 \mathrm{~mL}$ with water.

\subsection{Preparation of Idelalisib Stock solution:}

The standard stock solution of Idealisib was prepared at $1 \mathrm{mg} / \mathrm{mL}$ with mobile phase. The stock is further diluted with mobile phase to obtain $0.1 \mathrm{mg} / \mathrm{mL}$ solution.

\subsection{Preparation of Idelalisib Spiking Solutions $(4.6 \mu \mathrm{g} / \mathrm{mL}$ to $920 \mu \mathrm{g} / \mathrm{mL})$ :}

From the above Idelalisib stock solution 2 $(0.1 \mathrm{mg} / \mathrm{mL})$ take out $0.460 \mathrm{ml}, 1.380 \mathrm{ml}, 2.30 \mathrm{ml}$ and from the stock $1(1 \mathrm{mg} / \mathrm{mL})$ solution take out $1.150 \mathrm{ml}, 2.300 \mathrm{ml}, 4.600 \mathrm{ml}, 6.900 \mathrm{ml}$ and $9.200 \mathrm{ml}$ was pipette and transferred to 8 individual $10 \mathrm{ml}$ volumetric flask and make up the volume up to the mark with mobile phase to produce $4.6 \mu \mathrm{g} / \mathrm{mL}$, $13.8 \mu \mathrm{g} / \mathrm{mL}, 23 \mu \mathrm{g} / \mathrm{mL}, 115 \mu \mathrm{g} / \mathrm{mL}, 230 \mu \mathrm{g} / \mathrm{mL}$, $460 \mu \mathrm{g} / \mathrm{mL}, 690 \mu \mathrm{g} / \mathrm{mL}$ and $920 \mu \mathrm{g} / \mathrm{mL}$.

\subsection{Extraction procedure:}

To $250 \mu 1$ of drug free plasma $50 \mu 1$ of internal standard \& $10 \mu \mathrm{l}$ of Idelalisib was added. To the mixture $2 \mathrm{ml}$ of Acetonitrile was added, subjected to cyclomixer for $15 \mathrm{sec}$. Then vertexed for $2 \mathrm{~min}$ and finally centrifuged for $3 \mathrm{~min}$ at $3200 \mathrm{rpm}$ speed. After the centrifugation the organic layer was collected and directly injected $10 \mu \mathrm{L}$ into HPLC.

\subsection{Methodology for Analysis:}

A thorough and complete method of validation was following the USFDA guidelines. The method was validated for system suitability, auto sampler carryover, specificity and screening of biological matrix, sensitivity, matrix effect, linearity, precision and accuracy, recovery of analyte and internal standard, ruggedness on precision accuracy and linearity, reinjection reproducibility and stability on day zero, long batch, $\mathrm{LT}$ at $-28^{\circ} \mathrm{C}$ and LT at $-80^{\circ} \mathrm{C}$.

System suitability was done by MQC level sample as six homogenous injections and will see the \%RSD values for retention time and response of analyte and internal standard. Auto sample carryover was done by ULOQ and LLOQ level and check whether drug is remains or not in system.

Specificity and screening of biological matrix was done by LLOQ level of sample and check it for any interference of blank and sample response. Sensitivity was done by LLOQ level sample for to know the lowest limit of detection and calculate the $\%$ mean accuracy and \%CV. Matrix effect on analyte quantification with respect to consistency in signal (suppression/ enhancement), the matrix effect was checked in six different lots of Idelalisib plasma three replicates, each at LQC and HQC levels were prepared from these lots of plasma (total $36 \mathrm{QC}$ samples) and checked for the accuracy in terms of \% bias in all the QC samples. 
Linearity of the method was determined by analysis of standard plots associated with an 8-point standard calibration curve. Intra-batch and interbatch accuracy and precision was evaluated at five different concentrations levels (LLOQ, LQC, MQC and HQC) in six replicates for both the analytes. Mean values were obtained for calculated drug concentration over these batches. The accuracy and precision was calculated and expressed in terms of $\%$ Accuracy and coefficient of variation (\% CV), respectively. Recovery of the analytes from the extraction procedure was performed at LQC, MQC, and HQC levels. It was evaluated by comparing peak area of extracted samples (spiked before extraction) to the peak area of un extracted samples (quality control working solutions spiked in extracted plasma). Ruggedness can be done by changing the person to person for linearity, precision and accuracy in the levels of ULOQ, LQC, MQC and HQC.
Stability studies was performed as Zero hours, Long batch, $\mathrm{LT}$ at $-28^{\circ} \mathrm{C}$ and $\mathrm{LT}$ at $-80^{\circ} \mathrm{C}$. Day zero having two sample with six replicates of HQC and LQC levels. Long batch have 35replicates of LLOQ, LQC, MQC and HQC level of samples with $\%$ Mean accuracy. LT at $-28^{\circ} \mathrm{C}$ and LT at $-80^{\circ} \mathrm{C}$ have HQC and LQC level with \% Stability finding by comparison sample and stability sample.

\section{RESULTS AND DISCUSSIONS:}

3.1 System suitability: Six replicate samples of middle quality control samples of concentration along with internal standards were injected and \% $\mathrm{CV}$ was calculated. The \% $\mathrm{CV}$ of the retention time of analyte and IS was found to be $\leq 2.00 \%$. The $\%$ $\mathrm{CV}$ of the peak area ratio of analyte to IS was found to be $\leq 5.00 \%$. The results were found to be within limits and are summarized in Table 1.

TABLE 1: SYSTEM SUTABILITY DATA

\begin{tabular}{cccccc}
\hline \multirow{2}{*}{ Sample Name } & \multicolumn{2}{c}{ Analyte } & \multicolumn{2}{c}{ IS } & \multirow{2}{*}{ Area Ratio } \\
\cline { 2 - 5 } & Area & RT (min) & Area & RT (min) & 1.7871 \\
& 57496 & 7.19 & 32172 & 4.31 & 1.7872 \\
MQC & 57495 & 7.18 & 32170 & 4.30 & 1.7872 \\
& 57492 & 7.17 & 32168 & 4.32 & 1.7874 \\
& 57487 & 7.19 & 32162 & 4.30 & 1.7874 \\
MEAN & 57484 & 7.18 & 32160 & 4.32 & 1.7873 \\
SD & 57481 & 7.20 & 32161 & 4.31 & 0.000115 \\
\%CV & & 7.185 & & 4.310 & 0.01 \\
\hline
\end{tabular}

The carryover experiment was done to ensure that it does not affect the accuracy and precision. There was no carryover observed. The results were presented in Table 2.

TABLE 2: AUTO SAMPLER CARRYOVER

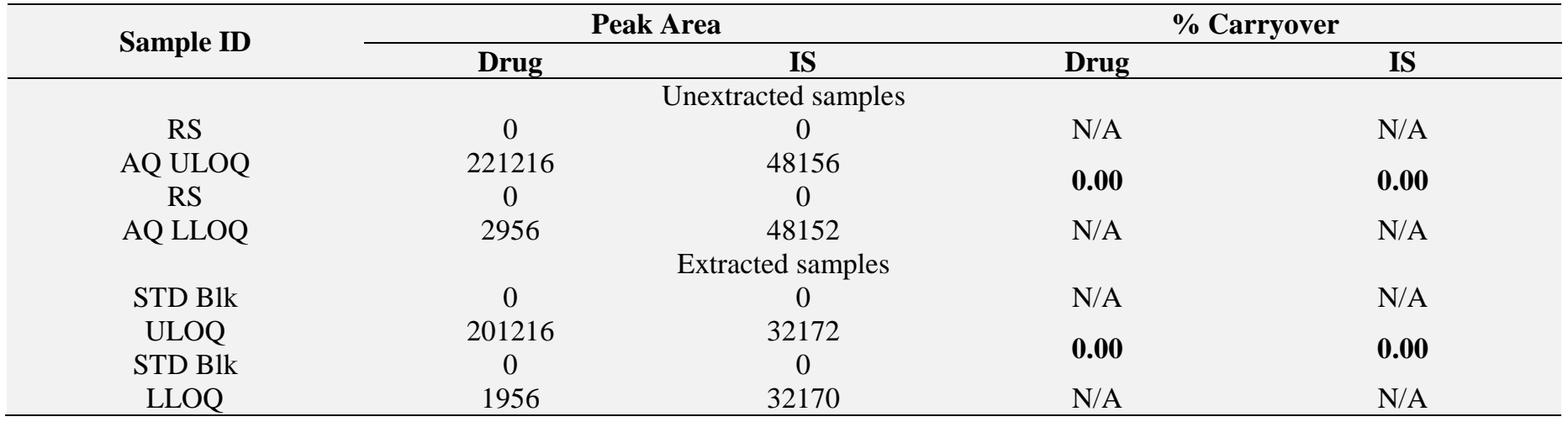

3.2 Specificity and screening of biological matrix: Response of interfering peaks in standard blank at the retention time of analyte should be $\leq 20.00 \%$ of that in LLOQ. Response of interfering peaks in standard blank at the retention time of IS should be $\leq 5.00 \%$ of that in LLOQ. All the 
samples were found to be free of interference at results were shown in Table 3. retention time of analyte in blank samples. The

TABLE 3: SPECIFICITY AND SCREENING OF BIOLOGICAL MATRIX

\begin{tabular}{|c|c|c|c|c|c|}
\hline \multirow{2}{*}{ Sample } & \multicolumn{2}{|c|}{ Response } & \multicolumn{2}{|c|}{ \% Interference } & \multirow{2}{*}{ Pass/Fail } \\
\hline & Drug & ISTD & Drug & ISTD & \\
\hline STD Blk1 & 0 & 0 & \multirow[b]{2}{*}{0.00} & \multirow[b]{2}{*}{0.00} & \multirow[b]{2}{*}{ Pass } \\
\hline LLOQ1 & 1956 & 32172 & & & \\
\hline STD Blk2 & 0 & 0 & \multirow{2}{*}{0.00} & \multirow{2}{*}{0.00} & \multirow{2}{*}{ Pass } \\
\hline LLOQ2 & 1952 & 32168 & & & \\
\hline STD Blk3 & 0 & 0 & \multirow{2}{*}{0.00} & \multirow{2}{*}{0.00} & \multirow{2}{*}{ Pass } \\
\hline LLOQ3 & 1991 & 32160 & & & \\
\hline STD Blk4 & 0 & 0 & \multirow{2}{*}{0.00} & \multirow{2}{*}{0.00} & \multirow{2}{*}{ Pass } \\
\hline LLOQ4 & 1982 & 32194 & & & \\
\hline STD Blk5 & 0 & 0 & \multirow{2}{*}{0.00} & \multirow{2}{*}{0.00} & \multirow{2}{*}{ Pass } \\
\hline LLOQ5 & 1943 & 32168 & & & \\
\hline STD Blk6 & 0 & 0 & \multirow{2}{*}{0.00} & \multirow{2}{*}{0.00} & \multirow{2}{*}{ Pass } \\
\hline LLOQ6 & 1968 & 32173 & & & \\
\hline
\end{tabular}

Sensitivity: The accuracy and precision of Idelalisib at LLOQ level was found to be $7.58 \%$ $\mathrm{CV}$ and \% Mean accuracy was found to be 100.58 . Acceptance Criteria is at least $67 \%$ (4 out of 6) of samples should be within 80.00-120.00\%. \% Mean accuracy should be within $80.00-120.00 \%$. \% CV accuracy should be $\leq 20.00 \%$. The results comply with acceptance limit and were incorporated in Table 4.

TABLE 4: SENSITIVITY DATA

\begin{tabular}{cc}
\hline & LLOQ \\
\cline { 2 - 2 } Sample & Nominal Concentration $(\mu \mathrm{g} / \mathrm{mL})$ \\
\cline { 2 - 2 } & 0.020 \\
& Calculated Concentration $(\mu \mathrm{g} / \mathrm{mL})$ \\
\hline 1 & 0.018 \\
3 & 0.020 \\
4 & 0.021 \\
5 & 0.022 \\
6 & 0.020 \\
N & 0.021 \\
Mean & 6 \\
SD & 0.0201 \\
$\%$ CV & 0.00153 \\
$\%$ Mean Accuracy & $\mathbf{7 . 5 8}$ \\
& $\mathbf{1 0 0 . 5 8}$ \\
\hline
\end{tabular}

3.4 Matrix effect: The matrix effect data of HQC and LQC were presented in Table 5. The Acceptance Criteria is at least $67 \%$ (2 out of 3) of samples at each level should be within 85.00$115.00 \%$. At least $80 \%$ (5 out of 6 ) of the matrix lot should be within the acceptance criteria. The \% mean accuracy of back calculated concentration of LQC and HQC samples prepared from different biological matrix lots should be within 85.00$115.00 \%$.

TABLE 5: MATRIX EFFECT

S. No. Plasma Lot No.

1

2
LOT1

LOT2

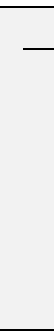

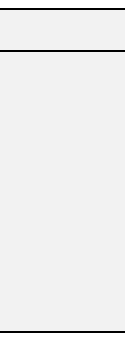

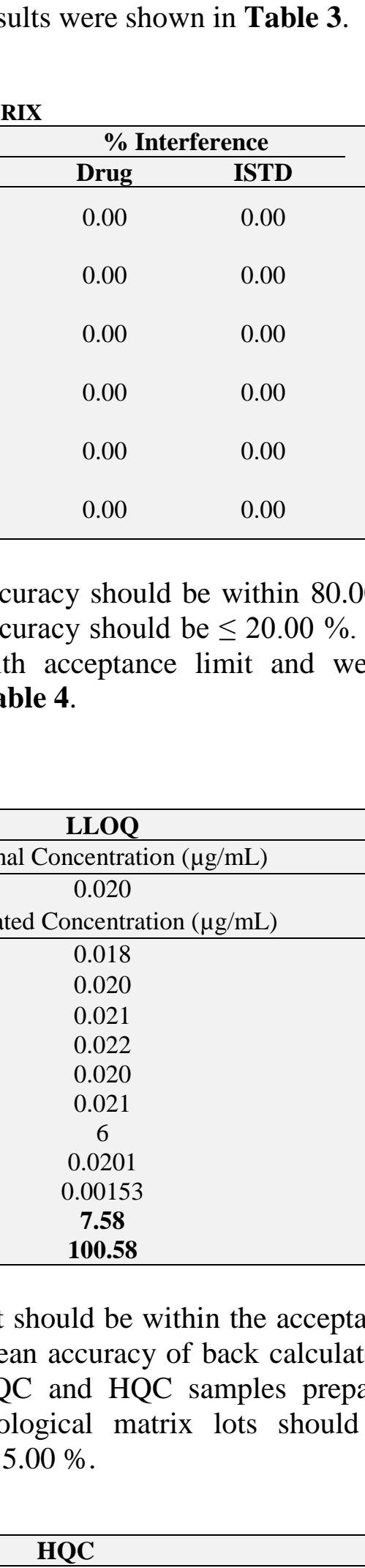




\begin{tabular}{cccc}
\hline 3 & LOT3 & 2.995 & 0.102 \\
4 & LOT4 & 2.871 & 0.095 \\
5 & LOT5 & 3.317 & 0.105 \\
6 & LOT6 & 3.174 & 0.102 \\
& Mean & 3.0102 & 0.1001 \\
& SD & 0.30948 & 0.00907 \\
& \% CV & 10.28 & 9.06 \\
& \% Mean Accuracy & 100.34 & 100.11 \\
& No. of QC Failed & 0 & 0 \\
\hline
\end{tabular}

3.5 Linearity: The calibration curve was found to represented in Fig.2. The data of calculated be linear at range $0.02-4 \mu \mathrm{g} / \mathrm{mL}$ with correlation calibration standards are presented in Table 6. coefficient $\left(\mathrm{r}^{2}\right)$ 0.999. The linear graph is

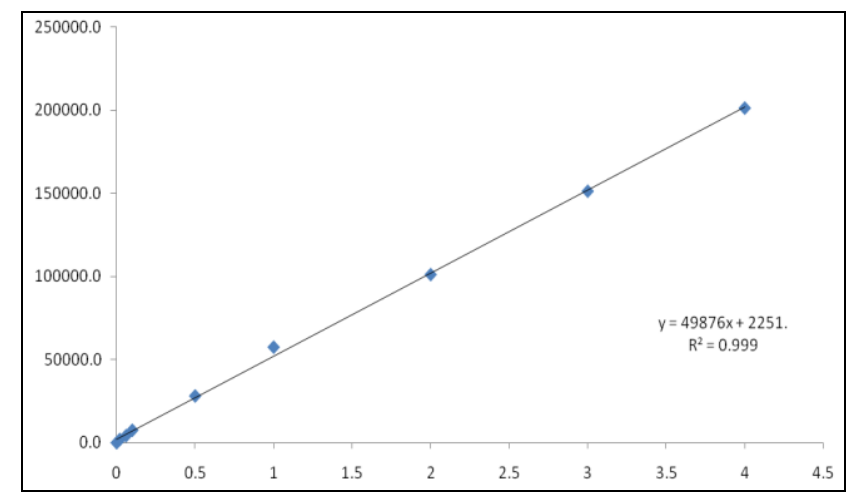

FIG.2: CALIBRATION PLOT FOR CONCENTRATION v/s AREA RATIO

TABLE 6: LINEARITY

\begin{tabular}{ccccccccc}
\hline S. No. & $\begin{array}{c}\text { Conc. } \\
(\boldsymbol{\mu g} / \mathbf{m l})\end{array}$ & \multicolumn{2}{c}{ Back Calculated Concentration $(\boldsymbol{\mu g} / \mathbf{m L})$} & & Avg. & \% CV & $\begin{array}{c}\text { \% Mean } \\
\text { Accuracy }\end{array}$ \\
\cline { 3 - 5 } & 0.02 & $\mathbf{1}$ & $\mathbf{2}$ & $\mathbf{3}$ & & 0.0197 & 7.77 & 98.33 \\
1 & 0.06 & 0.018 & 0.020 & 0.021 & & 0.0607 & 11.58 & 101.11 \\
2 & 0.1 & 0.092 & 0.060 & 0.068 & & 0.1020 & 9.80 & 102.00 \\
3 & 0.5 & 0.468 & 0.480 & 0.112 & & 0.4963 & 7.89 & 99.27 \\
4 & 1 & 0.862 & 1.125 & 1.148 & & 1.0450 & 15.21 & 104.50 \\
5 & 2 & 1.765 & 1.984 & 2.247 & & 1.9987 & 12.07 & 99.93 \\
6 & 3 & 2.580 & 3.195 & 3.389 & & 3.0547 & 13.83 & 101.82 \\
7 & 4 & 3.542 & 3.860 & 4.430 & 3.9440 & 11.41 & 98.60 \\
8 & & & & & & & \\
\hline
\end{tabular}

3.6 Precision: The \% CV of estimated concentrations for all four level quality control samples with six replicates for analyte was within 8.34 to $12.31 \%$. The \% mean accuracy for LLOQ, LOQ, MOQ and HQC was within $97.50 \%$ to $103.02 \%$. For inter day precision and accuracy the $\% \mathrm{CV}$ and accuracy results of all quality control samples were in between 8.36 to 11.44 and 99.61 to
102.40 respectively. The acceptance criteria is that at least $67 \%$ of total QC samples should be $\leq 15.00$ $\%$ and for the LLOQ, should be $\leq 20.00 \%$. \% Mean accuracy for LQC, MQC and HQC samples should be within 85.00-115.00 \% and for the LLOQ sample should be within 80.00-120.00\%. The data of precision and accuracy is complied in Table 7.

TABLE 7: PRECISION INTERDAY AND INTRADAY DATA

\begin{tabular}{ccccc}
\hline & HQC & MQC & LQC & LLOQ \\
\cline { 2 - 6 } Day 1 (n=6) & & Nominal Concentration $(\boldsymbol{\mu g} / \mathbf{m L})$ & 0.100 & \\
\cline { 2 - 6 } & & 3.000 & 1.000 & 0.020 \\
Mean & & & 0.1003 & 0.0203 \\
SD & 3.0907 & 0.9915 & 0.00918 & 0.00250 \\
\%CV & 0.25762 & 0.11947 & 9.15 & 12.31 \\
\hline
\end{tabular}


$\%$ Meay-2 $(\mathbf{n}=\mathbf{6})$
Den

$\%$ Mean Accuracy

Mean

SD

$\% \mathrm{CV}$

$\%$ Mean Accuracy

Day-3 (n=6)

$\begin{array}{cc}\text { Mean } & 3.0593 \\ \text { SD } & 0.27564 \\ \text { \%CV } & 9.01 \\ \text { ean Accuracy } & 101.98\end{array}$

Between Batch Precision and Accuracy $\mathrm{N}$

Mean

SD

$\% \mathrm{CV}$

$\%$ Mean Accuracy
103.02
3.0660
0.28528
9.30
102.20
3.0593
9.01

18

3.0720

0.25690

8.36

102.40
99.15
1.0098
0.12326
12.21
100.98
1.0110
0.12282
12.15
101.10

18
1.0041
0.11484
11.44
100.41

$\begin{array}{cc}100.33 & 101.67 \\ 0.0990 & 0.0200 \\ 0.00787 & 0.00237 \\ 7.95 & 11.83 \\ 99.00 & 100.00\end{array}$

0.0995

0.01003

10.09

99.50

18

0.0996

0.00854

8.57

99.61
0.0195

0.00187

9.59

97.50

18

0.0199

0.00215

10.80

99.72

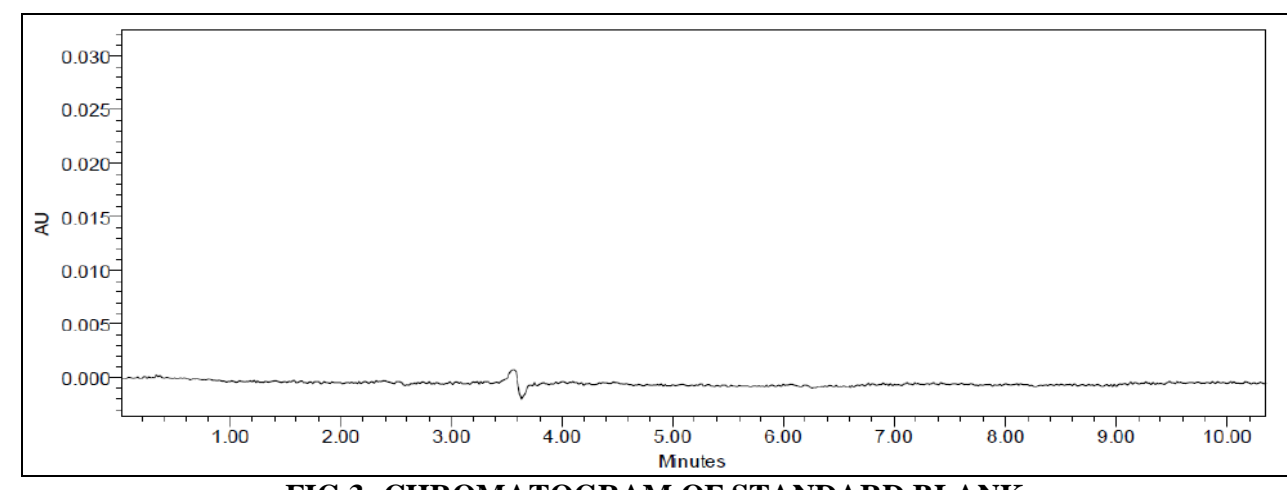

FIG.3: CHROMATOGRAM OF STANDARD BLANK

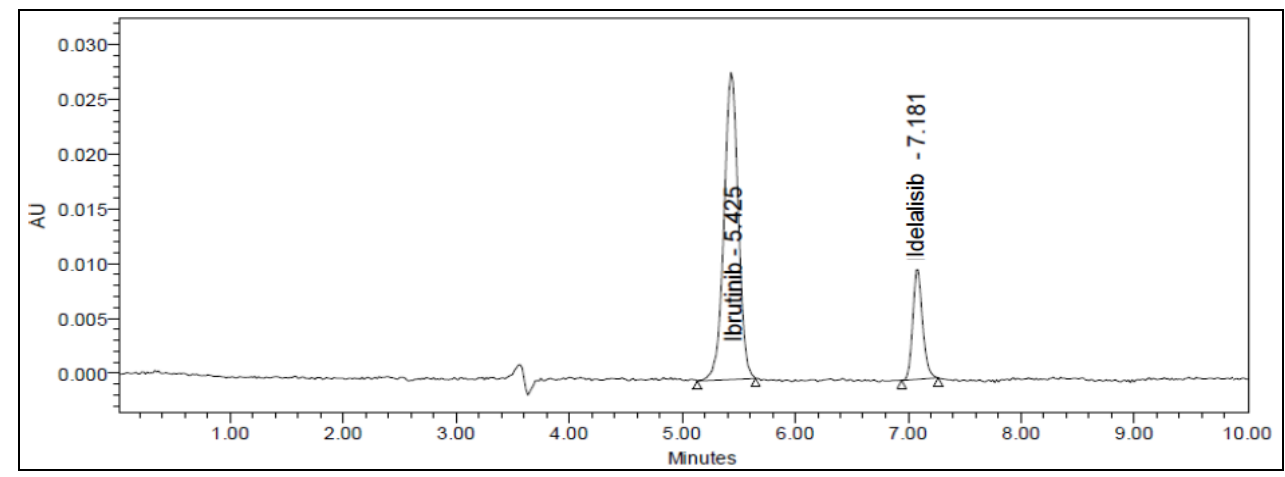

FIG.4: CHROMATOGRAM OF SEPARATION OF DRUG AND INTERNAL STANDARD

3.7 Recovery of analyte: The result of recovery study is given in Table $\mathbf{8}$ and $\mathbf{9}$. The results are within acceptance limit. The acceptable limit was
$\% \mathrm{CV}$ of recovery at each QC level and for IS should be $\leq 15.00 \%$. The overall mean recovery $\%$ CV for all QC levels should be $\leq 20.00 \%$.

TABLE 8: RECOVERY OF ANALYTE

\begin{tabular}{ccccccc}
\hline \multirow{2}{*}{ Sample } & \multicolumn{2}{c}{ HQC } & \multicolumn{2}{c}{ MQC } & \multicolumn{2}{c}{ LQC } \\
\cline { 2 - 7 } & $\begin{array}{c}\text { Un extracted } \\
\text { Response }\end{array}$ & $\begin{array}{c}\text { Extracted } \\
\text { Response }\end{array}$ & $\begin{array}{c}\text { Un extracted } \\
\text { Response }\end{array}$ & $\begin{array}{c}\text { Extracted } \\
\text { Response }\end{array}$ & $\begin{array}{c}\text { Un extracted } \\
\text { Response }\end{array}$ & $\begin{array}{c}\text { Extracted } \\
\text { Response }\end{array}$ \\
\hline Mean $(\mathrm{n}=6)$ & 186199.3 & 151624.2 & 63151.8 & 57828.0 & 8897.2 & 7549.3 \\
SD & 532.26 & 491.63 & 235.17 & 735.52 & 69.41 & 78.20 \\
$\% \mathrm{CV}$ & 0.29 & 0.32 & 0.37 & 1.27 & 0.78 & 1.04 \\
\% Mean & & & & 91.57 & & 84.85 \\
Recovery & & & & & &
\end{tabular}


Overall \%

Mean Recovery

Overall SD

Overall \% CV
85.951

5.1580

6.00

TABLE 9: REOVERY OF INTERNAL STANDARD

\begin{tabular}{ccc}
\hline S. no. & Un extracted Area Ratio & Extracted Area Ratio \\
\hline Mean $(\mathrm{n}=6)$ & 35742.7 & 32575.7 \\
SD & 339.40 & 481.29 \\
\% CV & 0.95 & 91.14 \\
\% Mean Recovery & & \\
\hline
\end{tabular}

\subsection{Ruggedness:}

The results of ruggedness study for Idelalisib was within acceptance limit. The data is represented in
Table 10. The precision and accuracy values for different columns with different analysts ranged from $5.61 \%$ to $12.49 \%$ and $98.63 \%$ to $104.13 \%$.

TABLE 10: RUGGEDNESS DATA

\begin{tabular}{|c|c|c|c|c|}
\hline \multirow[t]{6}{*}{ P\&A ID } & HQC & MQC & LQC & LLOQ \\
\hline & \multicolumn{4}{|c|}{ Nominal Concentration $(\mu \mathrm{g} / \mathrm{mL})$} \\
\hline & 3.000 & 1.000 & 0.100 & 0.020 \\
\hline & \multicolumn{4}{|c|}{ Nominal Concentration Range $(\mu \mathrm{g} / \mathrm{mL})$} \\
\hline & $(2.550-3.450)$ & $(0.850-1.150)$ & $(0.085-0.115)$ & $(0.016-0.024)$ \\
\hline & \multicolumn{4}{|c|}{ Calculated Concentration $(\mu \mathrm{g} / \mathrm{mL})$} \\
\hline \multicolumn{5}{|c|}{ Different Column } \\
\hline Mean $(n=6)$ & 2.9863 & 1.0081 & 0.1014 & 0.0200 \\
\hline $\mathrm{SD}$ & 0.25744 & 0.08270 & 0.00767 & 0.00200 \\
\hline$\% \mathrm{CV}$ & 8.62 & 8.20 & 7.56 & 10.00 \\
\hline$\%$ Mean Accuracy & 99.54 & 100.81 & 101.42 & 100.00 \\
\hline \multicolumn{5}{|c|}{ Different Analyst } \\
\hline Mean $(n=6)$ & 3.1240 & 0.9863 & 0.1050 & 0.0207 \\
\hline SD & 0.17517 & 0.6649 & 0.00623 & 0.00258 \\
\hline$\% \mathrm{CV}$ & 5.61 & 6.74 & 5.93 & 12.49 \\
\hline$\%$ Mean Accuracy & 104.13 & 98.63 & 105.02 & 103.33 \\
\hline
\end{tabular}

3.9 Stability studies: Zero hours, Long batch, LT at $-28{ }^{\circ} \mathrm{C}$ and $\mathrm{LT}$ at $-80^{\circ} \mathrm{C}$ results of LQC, MQC and HQC were found to more than $95 \%$, which is within acceptance limit. The results were complied in Table 11.

TABLE 11: STABILITY DATA

\begin{tabular}{|c|c|c|c|}
\hline Sample & Nominal Concentration $(\mu \mathrm{g} / \mathrm{mL})$ & $\begin{array}{l}\text { Mean Calculated Concentration } \\
(\mu \mathrm{g} / \mathrm{mL}) \pm \text { SD. }(\mathrm{n}=6)\end{array}$ & $\% \mathrm{CV}$ \\
\hline \multicolumn{4}{|c|}{ Stability on day zero } \\
\hline HQC & 3.000 & $3.1153 \pm 0.142$ & 4.57 \\
\hline LQC & $\begin{array}{l}0.100 \\
\text { Long batch at }-28^{\circ} \mathrm{C}\end{array}$ & $0.1022 \pm 0.008$ & 7.72 \\
\hline HQC & 3.000 & $3.0102 \pm 0.155$ & 5.17 \\
\hline LQC & 0.100 & $0.0979 \pm 0.012$ & 12.06 \\
\hline \multicolumn{4}{|c|}{ Long batch at $-80^{\circ} \mathrm{C}$} \\
\hline HQC & 3.000 & $3.0753 \pm 0.162$ & 5.76 \\
\hline LQC & 0.100 & $0.0952 \pm 0.006$ & 6.76 \\
\hline
\end{tabular}

CONCLUSION: The objective of this work was to develop a simple, cost-effective, rugged and sensitive method for determination of Idelalisb in plasma by using Ibrutinib as internal standard. The work shows less run time while comparing with other work articles. The total chromatographic runtime is $10.0 \mathrm{~min}$ with retention time for Idelalisib and IS at 7.185, and $4.310 \mathrm{~min}$, respectively. The method is validated over a dynamic linear range of $0.02-4 \mu \mathrm{g} / \mathrm{mL}$ for 
Idelalisib with a correlation coefficient of $\mathrm{r}^{2} 0.999$. The intra-batch and inter-batch precision (\%CV) across five levels (LLOQ, LQC, MQC, HQC, and ULOQ) is less than 13.53. This can be validated according to USFDA guidelines.

ACKNOWLEDGEMENTS: The authors are very much thankful for management of V.V. Institute of Pharmaceutical sciences, and Spectrum Pharma, India, for supporting to do this work.

CONFLICT OF INTEREST: The authors declare that there is no conflict of interests.

\section{REFERENCES:}

1. Raedler LA. Zydelig (Idelalisib): First-in-Class PI3 Kinase Inhibitor Approved for the Treatment of 3 Hematologic Malignancies. American Health \& Drug Benefits. 2015; 8(Spec Feature):157-162.

2. Richard R. Furman, M.D., Jeff P. Sharman et.al, Idelalisib and Rituximab in Relapsed Chronic Lymphocytic Leukemia. The new england journal of medicine. 2014 March, 370 (11).

3. S Ramanathan, F Jin, S Sharma, et. al, Clinical Pharmacokinetic and Pharmacodynamic Profile of Idelalisib. Clin Pharmacokinet. 2016 Jan; 55(1):33-45.
4. Graf SA, Gopal AK. Idelalisib for the treatment of nonHodgkin lymphoma. Expert Opin Pharmacother. 2016 Feb; 17(2):265-74.

5. Jennifer R. Brown, Idelalisib, an inhibitor of phosphatidylinositol 3-kinase $\mathrm{p} 110 \delta$, for relapsed/ refractory chronic lymphocytic leukemia. Blood. 2014 May 29; 123(22): 3390-3397.

6. National Center for Biotechnology Information. Pub Chem Compound Database; $\mathrm{CID}=11625818$, https://pubchem ncbi.nlm.nih.gov/compound/11625818 (accessed June 7, 2016).

7. Maddocks KJ, Ruppert AS, Lozanski G, et al. Etiology of Ibrutinib Therapy Discontinuation and Outcomes in Patients with Chronic Lymphocytic Leukemia. JAMA Oncol. 2015;1(1):80-87. doi:10.1001/jamaoncol.2014.218.

8. S. Cheng, J. Ma, A. Guo et al., "BTK inhibition targets in vivo CLL proliferation through its effects on B-cell receptor signaling activity," Leukemia, 2013,vol. 28, no. 3, pp. 649-657.

9. National Center for Biotechnology Information. PubChem Compound Database; CID=24821094, https://pubchem ncbi.nlm.nih .gov/compound/24821094 (accessed June 9, 2016).

10. U. S. Department of Health and Human Services, Food, and Drug Administration, Guidance for Industry, Bioanalytical Method Validation, U. S. Department of Health and Human Services, FDA, 2001.

How to cite this article:

Suneetha A and Sharmila D: Method development and validation for the estimation of Idelalisib in rabbit plasma by HPLC. Int J Pharm Sci Res 2016; 7(12): 4998-05.doi: 10.13040/IJPSR.0975-8232.7(12).4998-05.

All @ 2013 are reserved by International Journal of Pharmaceutical Sciences and Research. This Journal licensed under a Creative Commons Attribution-NonCommercial-ShareAlike 3.0 Unported License.

This article can be downloaded to ANDROID OS based mobile. Scan QR Code using Code/Bar Scanner from your mobile. (Scanners are available on Google Playstore) 